\title{
Prediction of cycle life of expansion bellows for fixed tube sheet heat exchanger
}

\author{
A. Chouiter, D. Benzerga \\ University of Sciences and Technology of Oran, Mechanical Department, B.P. 1505, 31000 Oran, Algeria \\ achouiter25@gmail.com,djeb_ben_@yahoo.fr
}

\author{
A. Haddi \\ University of Artois, EA 4515, Laboratoire de Génie Civil et géo-Environnement, Béthune F-62400, France \\ abdelkader.haddi@univ-artois.fr \\ T. Tamine \\ University of Sciences and Technology of Oran, Mechanical Department, B.P. 1505, 31000 Oran, Algeria \\ ttamine63@yahoo.fr
}

\begin{abstract}
Research on determining the lifetime of an expansion bellows designed to compensate the difference in expansion between the shell and the tubes in a fixed tube sheet heat exchanger has never ceased because of its Importance in a heat exchanger. The main function of the expansion bellows is to absorb the difference in expansion between the shell and the tube bundle while resisting the axial thermal deflection and the equivalent internal pressure on the shell side. TEMA-9 [1] edition attaches great importance to the finite element method in the case of an expansion bellows because of the disadvantages of the old design methods, which lead to overestimation and stress overload in the bellows. The objective of this work is to study the damage in the most stressed zone of the expansion bellows in order to construct a numerical simulation tool of the rupture to determine the lifetime that an expansion bellows can support during the operating conditions of a fixed tube heat exchanger. In a first step, the ANSYS FEM calculation code will allow the determination of the critical zone where the Von Mises is maximum and where potential cracks can develop. In a second step, a postprocessor based on the concept of Continuum Damage Mechanics and using Newton's iterative method will be applied to this critical area for the determination of the bellows critical lifetime. The maximum lifetime will be the value of the number of cycles that corresponds to the critical value of the DC damage (crack initiation).
\end{abstract}

KEYwORDs. Cycle life; Expansion bellow; Fixed tube sheet heat exchanger; Continuum damage mechanics; Damage; Finite element.

\section{OPEN ACCESS}

Citation: Chouiter, A., Benzerga, D., Haddi, A., Tamine. T., Prediction of cycle life of expansion bellows for fixed tube sheet heat exchanger, Frattura ed Integrità Strutturale, 47 (2019) 30-38.

Received: 13.07 .2018

Accepted: 22.11.2018

Published: 01.01.2019

Copyright: (C) 2019 This is an open access article under the terms of the CC-BY 4.0, which permits unrestricted use, distribution, and reproduction in any medium, provided the original author and source are credited. 


\section{INTRODUCTION}

7 he expansion bellows, which permit to compensate the difference in expansion between the tubular bundle and the shell in a fixed tube sheet heat exchanger, is a structural component formed by one or more convolutions. The expansion joint is an integral part of a heat exchanger.

It must simultaneously ensure the flexibility due to thermal expansion and withstand the internal pressure in the heat exchanger. In addition, it must be sufficiently flexible longitudinally to accommodate the deviations for which it is designed and must absorb the regular or irregular extension generated by the gradients temperature and pressure.

In the literature, we find a wide variety of references related to the calculation of expansion bellows cyclic life. We can cite as an example: Lee [2] has used a finite element analysis technique applied to the parameters of the bending and folding process of the metal bellows. Becht IV [3] has shown that the fatigue behavior of the bellows can be well predicted by dividing the bellows fatigue data on the basis of geometry parameters. Zupei [3] has used approximate calculation methods, which he compared to the results obtained by the finite element method for the U-shaped bellows. Broman et al. [5] determined the dynamic characteristics by manipulating the finite element parameters of the bellows beam. Kang et al. [6] have studied the process of forming different types of tubular bellows using a single stage hydroforming process. Faraji $[7,8]$ has experimentally and numerically analyzed the optimal parameters for the manufacture of metal expansion bellows. Bo-wun Huang et al [9], in their work, the dynamic properties of coupled tube-array structures with the axial loads are investigated in heat exchanger. Tingxin et al. [10] have experimentally studied the behavior of toroidal bellows compared to U-shaped bellows, they showed that toroidal bellows have a lower stress induced by internal pressure, longer fatigue life, greater ability to resist to instability of internal pressure and are more suited to situations of higher internal pressure. The Code ASME VIII div 1 [11] is widely the most comprehensive code that deal with the design of expansion bellows, their calculations as well as their standards.

In this work, we develop a method based on the concept of continuum damage mechanics (CDM), which reaches a stage of maturity allowing modeling any type of degradation. The life of the expansion bellows is obtained by using a post processor based on the of continuum damage mechanics using Newton's iterative method which is unconditionally stable and ensures good convergence.

In general, the damage is much localized and occupies a small volume, ie a representative volume element RVE compared to macroscopic scale of the structure. This is due to the high sensitivity to microscopic damage concentrations. Benzerga [12] noted that the damage effect on stress conditions occurs only in a very small area of the material. In other hand, the coupling damage behavior can occur only in RVE. It is the principle of the analysis of the local coupling damage-deformation presented by Lemaitre and Doghri [13]. Our approach can be divided into two stages: In a first step, the finite element calculation code (ANSYS) will allow in elasticity or elasto-plasticity to obtain the critical region of the structure $\left(\mathrm{M}^{*}\right)$ where the Von Mises stress is maximal. In a second step, a post processor based on the Continuum Damage Mechanics concept using the Newton iterative method was applied at this critical point $\left(\mathrm{M}^{*}\right)$ for the determination of the critical lifetime of the expansion bellows under service conditions of pressure and thermal expansion.

This lifetime is the value corresponding to the critical damage value Dc (crack initiation). This method was validated by comparing our numerical results with those of ASME code [11].

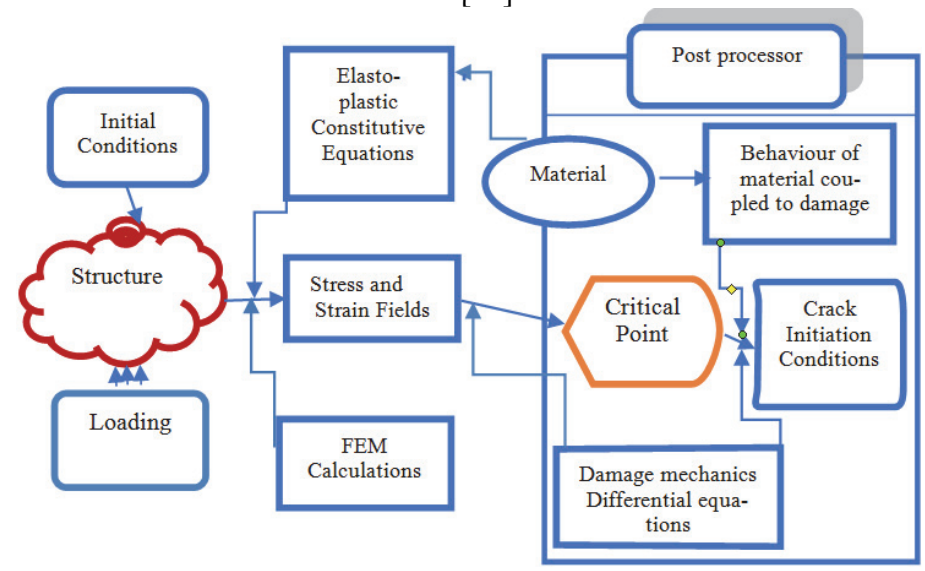

Figure 1: Locally coupled analysis of crack initiation. 


\section{MoDeling}

o model the bellows, we used the finite element ANSYS code. Due to symmetry, the design of the joint includes a two-dimensional axisymmetric half U-shape.

The dimensions of the structure are the inner radius and the thickness. For meshing the structure, we used 8 nodes quadrilateral axisymmetric elements. These elements have compatible displacement shape, and are well suited for modeling curved boundaries. The meshing in finite element models is the very important step in during analysis because it affects the accuracy and the economy of the solid model. The mesh used in 2D has 10802 elements and 22607 nodes (Fig. 2). For the boundary conditions, we respected the symmetry conditions and those of the experiment. Consequently, the following boundary conditions are used (Fig. 3): (i) the smaller diameter end (right side) is unrestrained axially and restrained in the radial direction, (ii) the large diameter end (left side) is restrained in the axial direction and unrestrained in the radial direction, (iii) the body is subjected to uniform pressure in shell side and displacement in axial direction.

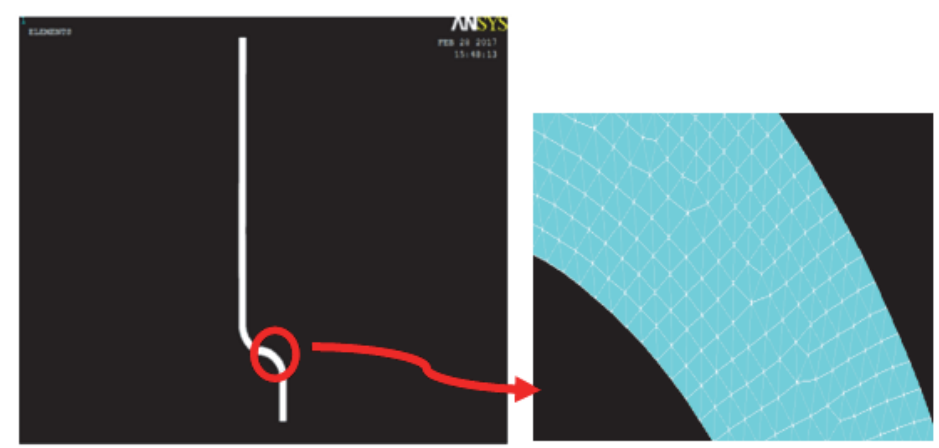

Figure 2: Meshing of the expansion bellows.

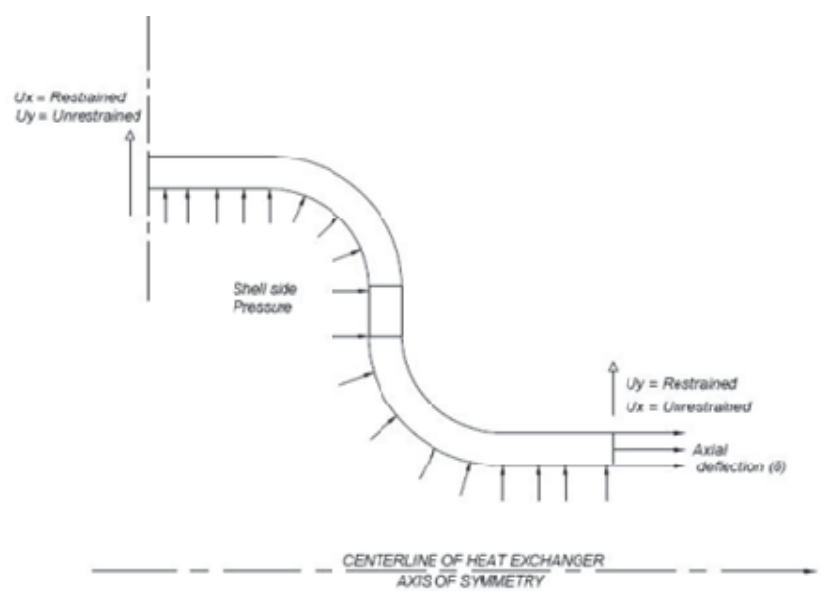

Figure 3: Boundary and loading conditions.

Using ANSYS finite element software, a subroutine has been developed and implemented in the main code for the determination of the most stressed area $\left(\mathrm{M}^{*}\right)$ at the curved boundaries (see Fig. 2) in which cracks can be developed.

The behavior of the critical point $\left(\mathrm{M}^{*}\right)$ where the equivalent stress $\sigma^{*}$ is maximal is obtained with the code ANSYS ${ }^{\circledR}$ and implanted in the post-processor using (Lemaitre and Doghri, [13]) damage model based on Newton iterative method. In continuum damage mechanics, a surface density of microcracks Lemaitre and Chaboche [14] defines the damage variable:

$$
D=\frac{\delta S_{D}}{\delta S}
$$




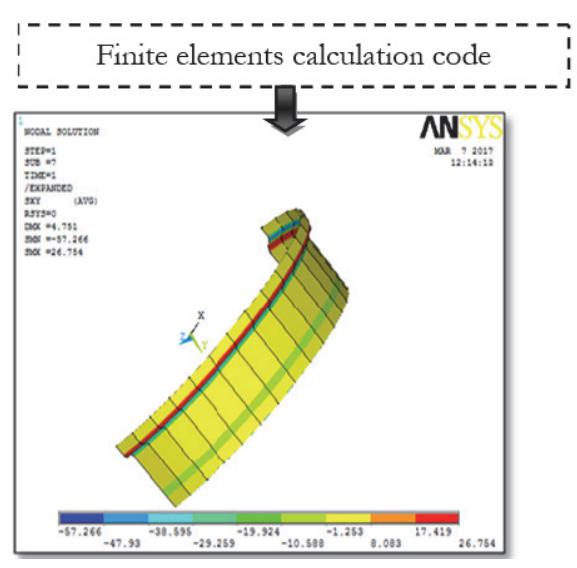

Critical area

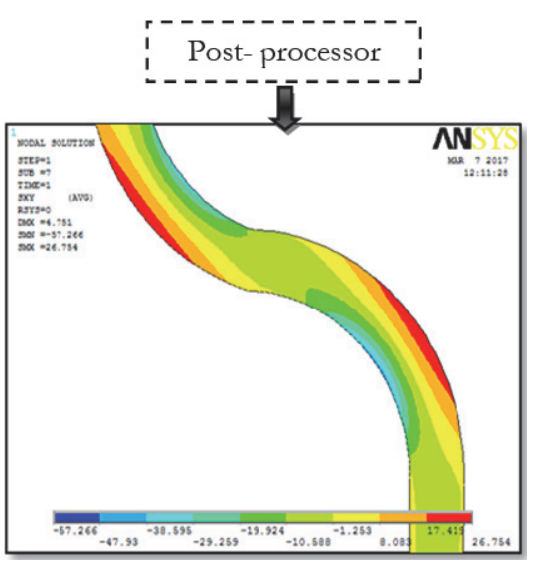

Critical point $\left(\mathrm{M}^{*}\right)$

Figure 4: Macroscopic-Microscopic scale.

If the damage is isotropic, $\mathrm{D}$ is a scalar allowing the introduction of the effective stress notion:

$$
\begin{aligned}
& \tilde{\sigma}=\frac{\sigma}{1-D} \\
& \sigma^{*}(M)=\sup \left(\sigma^{*}\right) \\
& \text { with } \quad \sigma^{*}=\sigma_{e q} R_{v}^{1 / 2} \\
& R_{V}=\frac{2}{3}(1+v)+3(1-2 v)\left(\frac{\sigma_{H}}{\sigma_{e q}}\right)^{2}
\end{aligned}
$$

$\mathrm{Rv}_{\mathrm{V}}$ is the triaxiality function which depends on the triaxiality coefficient $\sigma_{\mathrm{H}} / \sigma_{\mathrm{eq}}$, in most cases this criterion is satisfied in high stress concentration zones with high triaxiality coefficient value $\sigma_{\mathrm{H}} / \sigma_{\text {eq }}$.

The third step consists in determining the damage evolution by solving the constitutive laws below which will be written in incremental form and will have to be solved by Newton's numerical method Benallal et al. [14]:

$$
\begin{aligned}
& E_{i j}=E_{i j}^{e}+E_{i j}^{p} \\
& E_{i j}^{e}=\frac{1+v}{E} \frac{\sigma_{i j}}{1-D}-\frac{v}{E} \frac{\sigma_{k k}}{1-D} \delta_{i j} \\
& E_{i j}^{p}=\frac{3}{2} \frac{\tilde{\sigma}_{i j}^{D}}{\sigma_{e q}} \quad \text { if } \quad f=\dot{f}=0 \\
& D=\frac{\sigma_{e q}^{2}}{2 E S} R_{v} P \quad \text { if } \quad p \geq p_{0}
\end{aligned}
$$

\section{Numerical Procedure}

7 he method used for solving the above constitutive equations is integration schemes such as the radial return method M. Ortiz and E. P. Popov [16]. The method used is a strain driven algorithm: It is assumed in a first step that the stress values and the other variables of the model are known at the initial time $\left(t_{n}\right)$ and that the behavior is 
purely elastic.

Major headings should be typeset in boldface with the first letter of important words capitalized.

$$
\tilde{\sigma}=\lambda \operatorname{tr} \varepsilon 1+2 \mu\left(\varepsilon-\varepsilon_{n}^{p}\right)
$$

where $\lambda$ and $\mu$ are the Lamé coefficients and 1 is the identity tensor of order 2 .

All other "plastic" variables are equal to their values at time $\left(\mathrm{t}_{\mathrm{n}}\right)$. If this "elastic predictor" satisfies the condition of the load function $\mathrm{f} \leq 0$ (see Fig. 4), the assumption is then valid, and the calculation procedure for this time increment is completed. In the contrary case $f>0$, this elastic state is "corrected" according to the method below to determine the plastic solution:

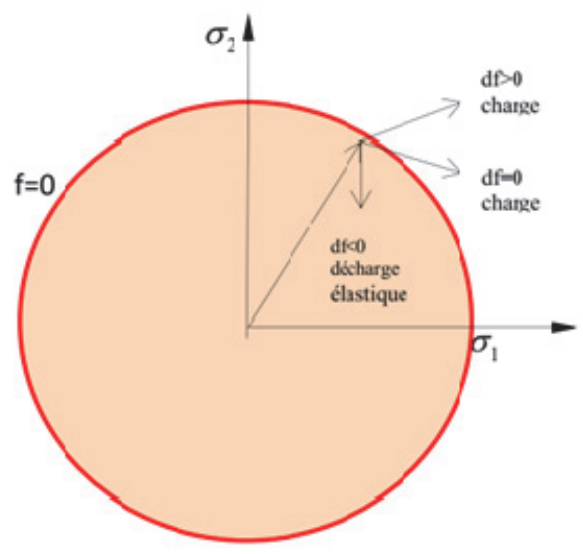

Figure 5: Plastic flow surface.

The constitutive laws (4) are discretized in an incremental form corresponding to the iterative method of Newton that has the advantage of being unconditionally stable (Lemaitre and Doghri, [13]). Consequently, the solutions to time $\left(\mathrm{t}_{\mathrm{n}}+1\right)$ must satisfy the following relations:

$$
\begin{aligned}
& f=\tilde{\boldsymbol{\sigma}}_{e q}-\sigma_{s}=0 \\
& \tilde{\boldsymbol{\sigma}}=\operatorname{tr} \boldsymbol{E} \boldsymbol{1}+2 \mu\left(\boldsymbol{E}-\boldsymbol{E}_{\boldsymbol{n}}^{\boldsymbol{p}}-\Delta \boldsymbol{E}^{\boldsymbol{p}}\right) \\
& \Delta \boldsymbol{E}^{\boldsymbol{p}}=N \Delta P \\
& \Delta D=\frac{Y}{S} \Delta P
\end{aligned}
$$

where:

$$
\Delta(\bullet)=(\bullet)_{n+1}-(\bullet)_{n} \quad \text { and } \quad N=\frac{2}{3}\left(\tilde{\sigma}^{D} / \tilde{\sigma}_{e q}\right)
$$

Substituting $\Delta \mathrm{E}^{\mathrm{P}}$ by its expression in the second equation, the problem is then reduced to two equations where the unknowns are $\tilde{\sigma}$ and $\mathrm{p}$ and must satisfy the system: 


$$
\begin{aligned}
& f=\tilde{\sigma}_{e q}-\sigma_{s} \\
& b=\tilde{\sigma}-\lambda \operatorname{tr} E 1-2 \mu\left(E-E_{n}^{p}\right)+2 \mu N \Delta P
\end{aligned}
$$

This nonlinear system is iteratively solved according to the Newton method (Benallal et al, [15]) for each iteration (s), we have:

$$
f+\frac{\partial f}{\partial \tilde{\sigma}}: c_{\tilde{\sigma}}=0 \quad ; \quad h+\frac{\partial h}{\partial \tilde{\sigma}}: c_{\tilde{\sigma}}+\frac{\partial h}{\partial p} c_{p}=0
$$

Where $\mathrm{f}$ and $\mathrm{h}$ is their partial derivatives taken at time $\left(\mathrm{t}_{\mathrm{n}}+1\right)$ at each iteration $(\mathrm{s})$. The "corrections" $c_{\tilde{\sigma}}$ and $\mathrm{Cp}$ are defined by:

$$
c_{\tilde{\sigma}}=(\tilde{\sigma})_{n+1}-(\tilde{\sigma})_{s} \text { and } \quad C_{p}=(P)_{S+1}-(P)_{S}
$$

The iteration $(\mathrm{s}=0)$ corresponds to the elastic predictor.

When $\mathrm{P}$ and $\tilde{\sigma}$ are determined, $\mathrm{E}^{\mathrm{P}}$ and $\mathrm{D}$ are calculated from their discretized forms and the stresses are determined by:

$$
\sigma_{i j}=(1-D)-\tilde{\sigma}_{i j}
$$

The method developed above has been implemented in the ANSYS commercial code and the post-processor. It will use as data, the parameters of the material and the components of the total deformations. As result, it will give, a function of the internal pressure in the fixed tube-plate heat exchanger and the difference of expansion exerted on the bellows, the damage value, the cumulative plastic deformation and the stress components $\sigma_{i j}$ at each step, until initiation of macroscopic cracks at the critical zone (Von Mises maximal stress value). This will permit to determine the number of maximum service cycles that the expansion bellows can withstand as a function of the variations in internal pressure and thermal expansion.

\section{VALIDATION OF The METHOdology}

A $s$ mentioned earlier in this paper, the objective of the present work is to develop a model that can predict the critical cycle life of expansion bellows for fixed tube sheet heat exchanger. As an example of application, we consider an expansion which material and geometrical properties has been taken from ASME Sec II Part D [17] (see Tab. 1 and Fig. 6).

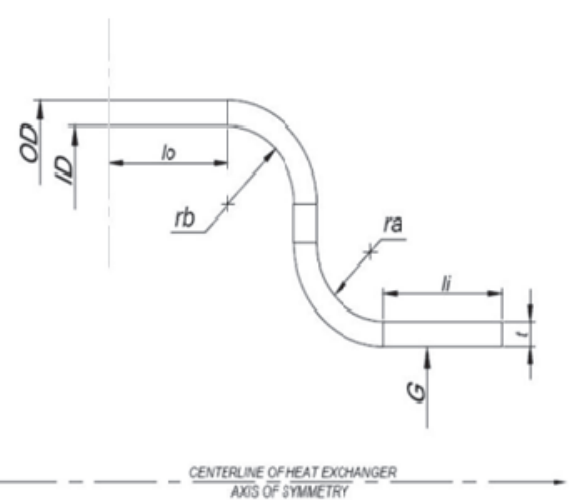

Figure 6: Two-dimensional model of wall expansion bellow. 


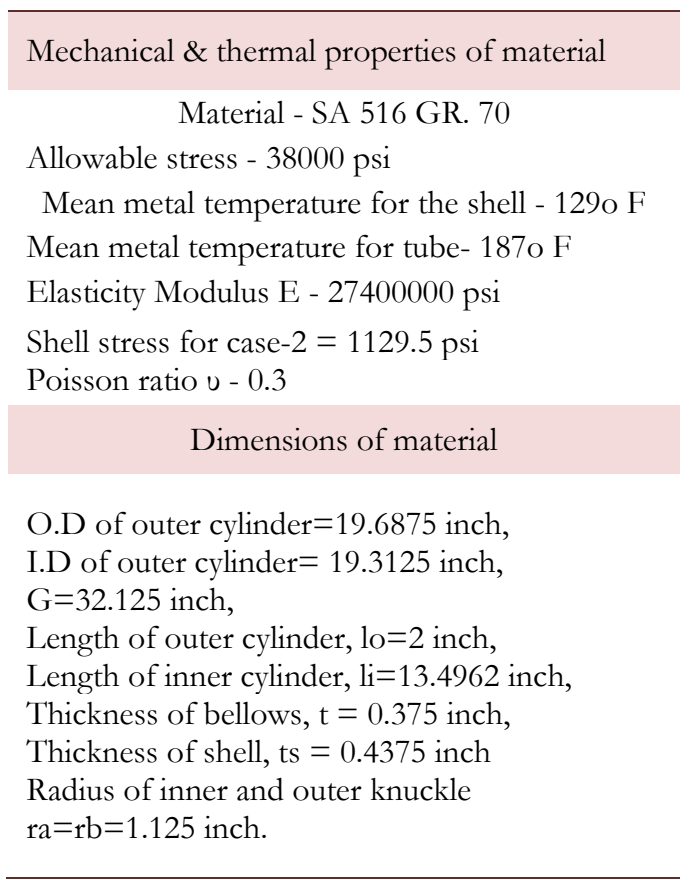

Table 1: Mechanical, thermal properties and Dimensions of material.

\section{OPERATING CONDITIONS}

he internal pressure of thick wall bellows is acting on shell side shell. The smaller diameter end is unrestrained in axial direction and restrained in radial direction and the large diameter end are restrained in the axial direction and unrestrained in radial direction (see Fig. 3 above). The loading in the axial direction is entered as displacement which is calculated as $\delta=(\mathrm{Ss} \times \mathrm{As}) / \mathrm{KFES}$ where Ss $=$ shell stress, As=shell cross-sectional area and KFSE=spring rate of main shell. In general, $\delta$ applied $=\delta(1 / 2 \mathrm{NFSE})$ where $\delta=$ amount of applied displacement and NFSE is total number of bellow.

The calculated applied displacement from shell stress is given in Tab. 2.

\begin{tabular}{cccc}
\hline Operating condition & $\begin{array}{c}\text { Shell side pressure } \\
(\mathrm{psi})\end{array}$ & $\begin{array}{c}\text { Shell stress } \\
(\mathrm{psi})\end{array}$ & $\begin{array}{c}\text { Applied displacement } \\
(\delta) \text { inch }\end{array}$ \\
$\begin{array}{c}\text { Shell side pr + Differential } \\
\text { expansion }\end{array}$ & 250 & 1129.58 & 0.02043 \\
\hline
\end{tabular}

Table 2: Operating conditions.

The result of life cycles to failure plots obtained from our proposed method and ASME VIII Div 1 are as shown in Fig. 7.

\section{ANALYSIS AND INTERPRETATION OF RESULTS}

$\mathrm{F}$ rom the results obtained, we can conclude that our results are quite close to the results obtained by ASME approach. . We can still optimize our results by decreasing the mesh so that we can get a fine mesh and results much more accurate. We calculated the results for a service condition, considering only the differential expansion and the internal pressure on the shell side, neglecting the tube-side pressure. Taking into account the tube-side pressure, our results will be even closer to reality. The results obtained using our model are lower than those of the ASME code, which will allow a safer and more secure design, hence the design is safe. 


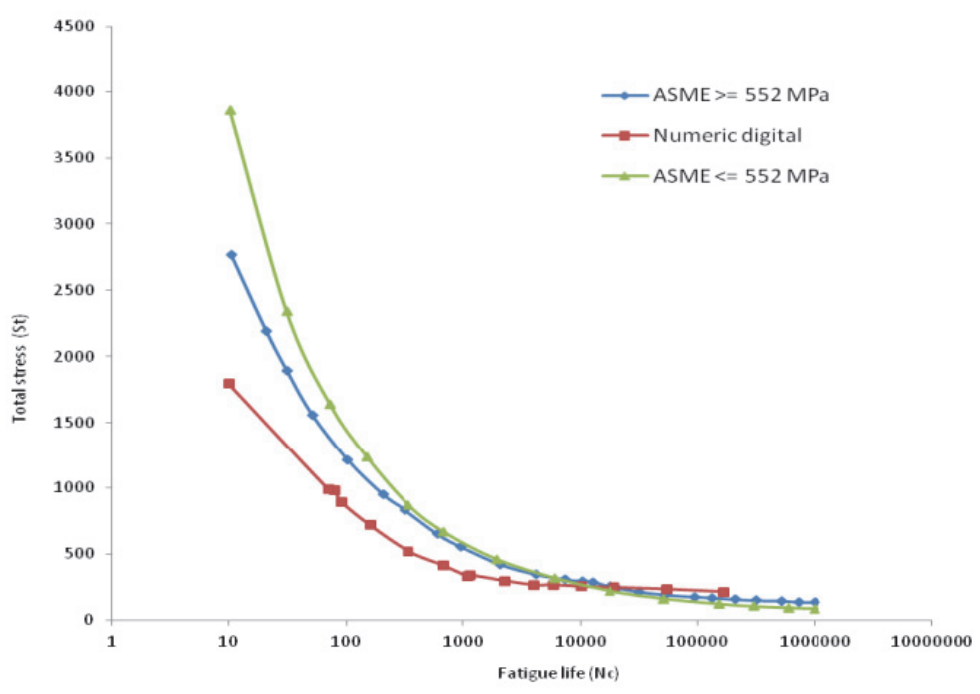

Figure 7: Cycle life of expansion bellow.

\section{CONCLUSIONS AND PERSPECTIVES}

$\mathrm{I}$ $\mathrm{n}$ this paper, we presented a new method based upon damage mechanics, which is now in its stage of maturity. Our main motivation in this work was to show that this method is a contribution to calculation of expansion bellow failure. In spite of some differences between proposed method results and the ASME results, our method has a good performance in predicting the bellow cycle life to failure. We believe that this work opens widely, the way to research and that its logical continuity should be based on the following points:

$\checkmark \quad$ From a theoretical point of view:

- Use of a surface of charge taking into account material strain hardeing;

- Using a damage anisotropic theory.

From the numerical point of view:

- Use of finite elements more robust.

\section{REFERENCES}

[1] TEMA9th. (2007). Standard of tubular exchanger manufacturers association. New York .Inc.

[2] Lee, S. (2002). Study on the forming parameters of the metal bellows. Journal of Materials Processing Technology, pp. $47-53$.

[3] Becht, C. B. (2000). Fatigue of bellows, a new design approach. International Journal of Pressure Vessels and Piping, pp. 843-850.

[4] Zupei, S. (1996). Approximate calculation of U-shaped bellows. Tsinghua Science and Technology, pp. 305 - 309.

[5] Broman, G., Jönsson, A and Hermann., M. (2000). Determining dynamic characteristics of bellows by manipulated beam finite elements of commercial software. International Journal of Pressure Vessels and Piping 77, pp. 445-453.

[6] Kang, H. W., Lee, I. H and Cho, D.-W. (2006). Development of a micro-bellows actuator using microstereolithography technology. Microelectronic Engineering, pp. 1201-1204.

[7] Faraji, G., Besharati, M. K., Mosavi, M and Kashanizadeh, H. (2008). Experimental and finite element analysis of parameters in manufacturing of metal bellows. The International Journal of Advanced Manufacturing Technology, pp. 641-648.

[8] Faraji, G., Mashhadi, M. M and Norouzifard, V. (2009). Evaluation of effective parameters in metal bellows forming process. Journal of Materials Processing Technology, pp. 3431-3437. 
[9] Bo-wun, H., Pu-ping, Y. and Jung-ge, T. (2016). Dynamic properties of coupled tube-array structures with the axial loads. Latine American Journal of Solids and Structures.

[10] Tingxin, L., Xiaoping, L., Tianxiang, L., Xigang, H and Xinfeng, L.(1995). Experimental research of toroid-shaped bellows behavior. International Journal of Pressure Vessels and Piping, pp. 141-146.

[11] CODE, A. B. (2010). ASME Rules for Construction of Pressure Vessels VIII Division 1. New York: the American society of mechanical engineers.

[12] Benzerga, D. (2015). Burst Pressure Estimation of Corroded Pipeline Using Damage Mechanics. Multiphysics Modelling and Simulation, Systems Design and Monitoring 2, pp. 481-488

[13] Lemaitre, J., Doghri, I. (1994). Damage 90: a post processor for crack initiation. Computer Methods in Applied Mechanics and Engineering, pp. 197-232.

[14] Lemaitre, J,.Chaboche, J.L. (1988). Mechanics of solids material, Cambridge university press.

[15] Benallal, A., Billardon R. and Doghri, I. (1988). An integration algorithm and the corresponding consistent tangent operator for fully coupled elastoplastic and damage equations. International Journal for Numerical Methods in Biomedical Engineering (E4), pp. 731-740.

[16] Ortiz, M., Popov, E. P.(1985).Accuracy and stability of integration algorithms for elastoplastic constitutive relations. International Journal for Numerical Methods in Engineering, pp. 1561-1576.

[17] CODE, A. B. (2004). ASME boiler and pressure vessel II part D. New York: the American society of mechanical engineers. 